\title{
Posttransplant survival is not diminished in heart transplant recipients bridged with implantable left ventricular assist devices
}

\author{
Mark J. Russo, MD, MS, ${ }^{a}$ Kimberly N. Hong, MHSA, ${ }^{\text {a,b }}$ Ryan R. Davies, MD, ${ }^{a}$ Jonathan M. Chen, MD, ${ }^{a}$ \\ Robert A. Sorabella, BA, ${ }^{a}$ Deborah D. Ascheim, MD, ${ }^{b}$ Mathew R. Williams, MD, ${ }^{a}$ \\ Annetine C. Gelijns, PhD, ${ }^{\mathrm{b}}$ Allan S. Stewart, MD, ${ }^{\mathrm{a}}$ Michael Argenziano, MD, ${ }^{\mathrm{a}}$ and \\ Yoshifumi Naka, MD, $\mathrm{PhD}^{\mathrm{b}}$
}

\begin{abstract}
Background: The purpose of this study was to compare posttransplantation morbidity and mortality in orthotopic heart transplant recipients bridged to transplant with a left ventricular assist device with nonbridged recipients. To account for potential differences across device types, we stratified bridge-to-transplant recipients by type of ventricular assist device: extracorporeal (EXTRA), paracorporeal (PARA), and intracorporeal (INTRA).
\end{abstract}

\begin{abstract}
Methods: The United Network for Organ Sharing provided de-identified patient-level data. The study population included 10,668 orthotopic heart transplant recipients aged 18 years old or older and undergoing transplantation between January 1, 2001, and December 31, 2006. Follow-up data were provided through August 3, 2008, with a mean follow-up time of $3.17 \pm 2.15$ years (range, $0-8.11$ years). The primary outcome was actuarial posttransplant graft survival. Other outcomes of interest included infection, stroke, and dialysis during the transplant hospitalization; primary graft failure at 30 days; transplant hospitalization length of stay; and long-term complications including diabetes mellitus, transplant coronary artery disease, and chronic dialysis. Multivariable Cox proportional hazards regression (backward, $P<.15$ ) was used to determine the relationship between groups and overall graft survival, and multivariable logistic regression analysis (backward, $P<.15$ ) was used to determine the relationship between groups and secondary outcome measures.
\end{abstract}

Results: In multivariable Cox regression analysis, when compared with the nonbridged group, risk-adjusted greater than 90-day graft survival was diminished among the EXTRA group (hazard ratio $=3.54,2.28-5.51, P<.001$ ), but not the INTRA group $(1.04,0.719-1.51, P=.834)$ or the PARA group $(1.06,0.642-1.76, P=.809)$. There were no significant differences in risk-adjusted graft survival across the 4 groups during the 90 -days to 1-year or 1- to 5-year intervals. However, at more than 5 years, risk-adjusted graft survival in the INTRA group $(0.389,0.205-0.738, P=$ .004 ) was better than in the nonbridged group. The EXTRA, PARA, and INTRA groups all experienced increased risks of infection. The EXTRA group had increased risks of dialysis, stroke, and primary graft failure at 30 days, whereas neither the PARA nor the INTRA group differed from the nonbridged group. Long-term complications did not differ by group.

Conclusion: The use of implantable left ventricular assist devices as bridges to transplantation, including both intracorporeal and paracorporeal devices, is not associated with diminished posttransplant survival. However, 90-day survival was diminished in recipients bridged with extracorporeal devices. (J Thorac Cardiovasc Surg 2009;138:1425-32)

\section{Supplemental material is available online.}

\footnotetext{
From the Division of Cardiothoracic Surgery, ${ }^{\text {a }}$ Columbia University, New York, NY; and Department of Health Policy, ${ }^{\mathrm{b}}$ Mount Sinai Medical Center, New York, NY. Disclosures: This work was supported in part by Health Resources and Services Administration contract 231-00-0115. The content is the responsibility of the authors alone and does not necessarily reflect the views or policies of the Department of Health and Human Services, nor does mention of trade names, commercial products, or organizations imply endorsement by the U.S. Government.

Received for publication July 25, 2008; revisions received June 17, 2009; accepted for publication July 14, 2009.

Address for reprints: Yoshifomi Naka, MD, PhD, New York-Presbyterian Hospital/ Columbia, Milstein Hospital Bldg Room 7-435 GN, 177 Fort Washington Ave, New York, NY 10032 (E-mail: yn33@columbia.edu).

$0022-5223 / \$ 36.00$

Copyright (C) 2009 by The American Association for Thoracic Surgery

doi:10.1016/j.jtcvs.2009.07.034
}

Ventricular assist devices (VADs) are crucial in the management of heart transplant candidates whose condition becomes refractory to medical therapy while they are awaiting transplantation. $^{1,2}$ Over the past decade, the number of heart transplant recipients supported by VADs at the time of transplantation has more than doubled to over 400 per year. $^{3}$

Although numerous studies have demonstrated the benefits of VADs in the pretransplant period, ${ }^{1,2}$ findings from studies examining the impact of VADs on posttransplant outcomes have conflicted. The majority of studies have concluded that short-term, but not long-term, survival is diminished in recipients bridged with VADs. ${ }^{4.5}$ More recently, an analysis of the United Network for Organ Sharing (UNOS) registry ${ }^{6}$ concluded that during the study period (1995-2004), there was a significant increase in late, but not early, mortality among those implanted with intracorporeal devices. 


\section{Abbreviations and Acronyms \\ BTT = bridge to transplantation \\ EXTRA $=$ extracorporeal ventricular assist device \\ INTRA $=$ intracorporeal ventricular assist device \\ LVAD $=$ left ventricular assist device \\ PARA = paracorporeal ventricular assist device \\ UNOS = United Network for Organ Sharing \\ $\mathrm{VAD}=$ ventricular assist device}

The purpose of this study was to compare posttransplantation survival in nonbridged orthotopic heart transplant recipients with survival of recipients bridged to transplant (BTT) with extracorporeal (EXTRA), paracorporeal (PARA), and intracorporeal (INTRA) left ventricular assist devices (LVADs) during the period 2001 through 2006. Furthermore, this study examined the relationship between VADtype and in-hospital morbidity, including stroke, infection, and need for dialysis; primary graft failure at 30 days; transplant hospitalization length of stay; and the long-term complications including diabetes mellitus, transplant coronary artery disease, chronic dialysis, and rejection.

For this analysis, we chose to focus on the more recent period, because VAD technology and its application have undergone important changes since the completion of REMATCH (Randomized Evaluation of Mechanical Assistance for the Treatment of Congestive Heart Failure) in 2001. ${ }^{7}$ First, there have been incremental improvements in the device by manufacturers. ${ }^{8}$ Concurrently, with growing experience, clinicians have improved their management of LVAD patients including modifications in the operative procedure, adoption of practices that decrease driveline infections, and changes in anticoagulation regimens, which reduced the adverse event profile associated with devices. With these advances, a number of investigators have reported improved clinical as well as economic outcomes ${ }^{9,10}$ with device therapy. In addition, this period includes early experience with newer generation pulsatile devices. Therefore, this more recent period may be more generalizable to the current era.

\section{METHODS \\ Data Collection}

Use of these data is consistent with the regulations of Columbia University's Institutional Review Board. UNOS provided de-identified event-level data from the Thoracic Registry (data source \#030309-3), where each observation represents a heart transplant. These data include all heart transplants and associated donors in the United States and reported to the Organ Procurement and Transplantation Network since October 1987. Data entry by all US transplant centers is mandated by the 1984 National Transplantation Act.

\section{Study Population}

The study population included 10,989 orthotopic heart transplants among recipients aged 18 years old or more and undergoing transplanta- tion between January 1, 2001, and December 31, 2006. Follow-up data were provided through February 20, 2009. Recipients were stratified into 4 groups: standard/nonbridged (non-BTT), extracorporeal (EXTRA), intracorporeal (INTRA), and paracorporeal (PARA). EXTRA devices included Abiomed BVS5000 (Abiomed Inc, Danvers, Mass), TandemHeart (Cardiac Assist, Inc, Pittsburgh, Pa), Bio-Medicus (Medtronic Bio-Medicus, Eden Prairie, Minn), and Levitronix/Centrimag (Levitronix LLC, Waltham, Mass). PARA devices included Abiomed AB5000, Thoratec PVAD (Thoratec Corporation, Pleasanton, Calif), and Toyobo (Toyobo, Osaka, Japan). INTRA devices included pulsatile devices (Novacor [Novacor; World Heart Inc, Oakland, Calif], HeartMate I [Thermo Cardiosystems, Inc, Woburn, Mass], Thoratec IVAD, and LionHeart [Arrow International, Inc, Reading, Pa]) and continuous-flow devices (HeartMate II, MicroMed/Debakey [MicroMed Technology Inc., Houston, Tex], Jarvik [Jarvik Heart, Inc, New York, NY], and Ventracor/VentrAssist [Ventracor, Sydney, Australia). Devices designated as "Abiomed" only were classified as "Abiomed BVS5000," and devices designated as "Thoratec" only were classified as "Thoratec PVAD." In secondary analysis, the INTRA group was substratified into pulsatile and continuous-flow groups. Because the purpose of the study was to better understand survival in BTT with LVADs, recipients were excluded if they were supported with a total artificial heart $(\mathrm{n}=49,0.45 \%)$, extracorporeal membrane oxygenation $(\mathrm{n}=40,0.36 \%)$, a right $\operatorname{VAD}(\mathrm{n}=22,0.20 \%)$, or if the VAD type was unknown $(\mathrm{n}=14,0.13 \%)$. In addition, patients who underwent a simultaneous transplant of another organ $(n=255,2.32 \%)$ were excluded.

\section{Outcome Measures}

The primary outcome measure was actuarial posttransplant graft survival. Risk-adjusted survival, derived from multivariate Cox regression analysis, was expressed as hazard ratios with $95 \%$ confidence intervals. Secondary outcome measures included transplant hospitalization morbidity measured by incidence of stroke, infection, and need for dialysis during the transplant hospitalization, as well as primary graft failure at 30 days. Long-term complications, which were reported as incidence rates, included diabetes, transplant coronary artery disease, chronic dialysis, and severe rejection.

\section{Data Analysis}

Continuous variables were reported as means \pm standard deviations and compared by the Student $t$ test. The $\chi^{2}$ test was used to compare categorical variables. All reported $P$ values are 2 sided.

\section{Survival and Other Time-to-Event Analyses}

Kaplan-Meier analysis was used to calculate actuarial survival. For survival analysis, the outcome of interest was death $(n=2585,24.3 \%)$ or retransplantation $(\mathrm{n}=119,1.11 \%)$. Other patients, including those lost to follow-up $(\mathrm{n}=363,3.40 \%)$ or alive at last follow-up $(\mathrm{n}=7601$, $71.3 \%$ ), were censored on the day of last known follow-up. To assess the simultaneous effect of multiple variables on graft survival after heart transplant, we used multivariable Cox proportional hazards regression (backward, $P<.15$ ) to determine the relationship between groups and overall graft survival. Proportional hazards assumption was examined for each of the variables using the Schoenfeld residuals test to assess proportionality. For variables demonstrating a significant interaction with time, the interaction term with time was included in the final regression model. Because the relationship between survival and VAD type was found to be time dependent, the hazard ratios for VAD types during various time intervals ( $<90$ days, 90 days -1 year, $1-5$ years, and $>5$ years) were reported. Multivariable logistic regression analysis (backward, $P<.15$ ) was used to determine the relationship between groups and secondary outcome measures. Long-term complications were reported as incidence rates per 100 patient-years. 


\section{RESULTS}

\section{Study Population (Table 1)}

Analysis included 10,668 orthotopic heart transplants with a mean follow-up time of $3.54 \pm 2.10$ years (range, 0-8.11 years). Recipients were stratified into 4 groups: INTRA $(\mathrm{n}=1680,15.7 \%)$, PARA $(\mathrm{n}=514,4.8 \%)$, EXTRA $(\mathrm{n}=128,1.2 \%)$, and non-BTT $(\mathrm{n}=8346,78.2 \%)$.

Posttransplant survival. Unadjusted graft survival (Figure 1) was not different in the INTRA $(P=.737)$ group when compared with the non-BTT group; however, when compared with the non-BTT group, survival was significantly worse in the EXTRA group $(P<.001)$ and the PARA group $(P<.001)$. In multivariate Cox regression analysis (Appendix E1), when compared with the non-BTT group, risk-adjusted less than 90-day graft survival was diminished among the EXTRA group (hazard ratio $=3.54,2.28-5.51, P<.001)$, but not the INTRA group $(1.04,0.719-1.51, P=.834)$ or PARA group (1.06, 0.642-1.76, $P=.809$ ). There were no significant differences in risk-adjusted graft survival across the 4 groups during the 90 -days to 1 -year interval or 1 - to 5year interval. However, at more than 5 years, risk-adjusted graft survival in the INTRA group $(0.389,0.205-0.738, P$ $=.004$ ) was better than in the non-BTT group (Figure 2).
Transplant hospitalization morbidity: Infection, dialysis, and stroke (Figure 3). The EXTRA, PARA, and INTRA groups all experienced increased incidence of infection. The EXTRA group had increased risk of dialysis, stroke, and primary graft failure at 30 days, whereas neither the PARA nor the INTRA group differed from the non-BTT group. Length of stay (Figure 4) was significantly longer in all VAD groups compared with the non-BTT groups.

Long-term complications of transplantation: Renal failure, diabetes, transplant coronary artery disease, severe rejection (Figure 5). There were no differences in the incidence rates of the long-term complications of transplantation between the non-BTT group and any of the VAD groups.

Implantable pulsatile devices versus continuous-flow devices. When the INTRA group was further stratified into continuous-flow and pulsatile groups and compared with the non-BTT group by multivariate Cox regression analysis, no differences in the following survival data were found: risk-adjusted 90-day survival (pulsatile: 1.03, 0.70-1.50, $P=.888$; continuous flow: 1.13 , $0.58-2.20, P=.722$ ), 90-day to 1 -year survival (pulsatile: $0.78,0.48-1.27, P=.323$; continuous flow: 1.15 , $0.54-2.46, P=.719$ ), and 1-year to 5-year survival (pulsatile: $0.82,0.679-1.01, P=.064$; continuous-flow:

TABLE 1. Pretransplant recipient characteristics

\begin{tabular}{|c|c|c|c|c|c|c|c|c|}
\hline & Non-BTT & INTRA & $P$ value* & PARA & $P$ value* & EXTRA & $P$ value* & Total \\
\hline No. & 8346 & 1680 & & 514 & & 128 & & 10,668 \\
\hline$(\%)$ & 78.2 & 15.7 & & 4.82 & & 1.20 & & 100.0 \\
\hline Recipient age (y) & 52.2 & 50.5 & $<.001$ & 46.3 & $<.001$ & 49.1 & .005 & 51.6 \\
\hline $\mathrm{SD}$ & 12.3 & 11.4 & & 14.2 & & 13.7 & & 12.3 \\
\hline Recipient BMI $\left(\mathrm{kg} / \mathrm{m}^{2}\right)$ & 26.4 & 27.4 & $<.001$ & 27.6 & $<.001$ & 26.0 & .4073 & 26.5 \\
\hline $\mathrm{SD}$ & 4.8 & 5.1 & & 5.1 & & 4.5 & & 4.9 \\
\hline Etiology: ischemic (n) & 3708 & 822 & $<.001$ & 220 & .397 & 62 & .245 & 4812 \\
\hline$\%$ & 44.4 & 48.9 & & 42.8 & & 48.4 & & 45.1 \\
\hline Etiology: DCM & 3116 & 716 & $<.001$ & 215 & $<.001$ & 35 & .029 & 4082 \\
\hline$\%$ & 37.3 & 42.6 & & 41.8 & & 27.3 & & 38.3 \\
\hline Wait time (d) & 224.4 & 240.3 & .13 & 152.1 & $<.001$ & 79.0 & $<.001$ & 221.6 \\
\hline $\mathrm{SD}$ & 400.3 & 354.9 & & 310.8 & & 203.5 & & 388.4 \\
\hline Status 1A (n) & 2134 & 1071 & $<.001$ & 395 & $<.001$ & 109 & $<.001$ & 3709 \\
\hline$\%$ & 25.6 & 63.8 & & 76.8 & & 85.2 & & 34.8 \\
\hline ICU at transplant (n) & 2376 & 392 & $<.001$ & 219 & $<.001$ & 106 & $<.001$ & 3093 \\
\hline$\%$ & 28.5 & 23.3 & & 42.6 & & 82.8 & & 29.0 \\
\hline Ventilator at transplant (n) & 138 & 36 & .172 & 43 & $<.001$ & 59 & $<.001$ & 276 \\
\hline$\%$ & 1.7 & 2.1 & & 8.4 & & 46.1 & & 2.6 \\
\hline Previous transplant (n) & 250 & 9 & $<.001$ & 11 & .263 & 13 & $<.001$ & 283 \\
\hline$\%$ & 3.0 & 0.5 & & 2.1 & & 10.2 & & 2.7 \\
\hline Inotropes at transplant (n) & 4230 & 326 & $<.001$ & 156 & $<.001$ & 79 & $<.001$ & 4791 \\
\hline$\%$ & 50.7 & 19.4 & & 30.4 & & 61.7 & & 44.9 \\
\hline Previous transplant within 90 days (n) & 11 & 1 & .434 & 5 & $<.001$ & 13 & $<.001$ & 30 \\
\hline$\%$ & 0.1 & 0.1 & & 1.0 & & 10.2 & & 0.3 \\
\hline Previous cardiac surgery $\dagger$ (n) & 1492 & 1015 & .001 & 308 & $<.001$ & 66 & $<.001$ & 2881 \\
\hline$\%$ & 17.9 & 60.4 & & 59.9 & & 51.6 & & 27.0 \\
\hline
\end{tabular}

Non-BTT, Nonbridge to transplant; INTRA, intracorporeal ventricular assist device; PARA, paracorporeal ventricular assist device; EXTRA, extracorporeal ventricular assist device. $S D$, standard deviation; $B M I$, body mass index; $D C M$, dilated cardiomyopathy; $I C U$, intensive care unit. * $P$ values determined using standard deviation at the comparison group. $\dagger$ Previous cardiac surgery excludes VAD implantation. 


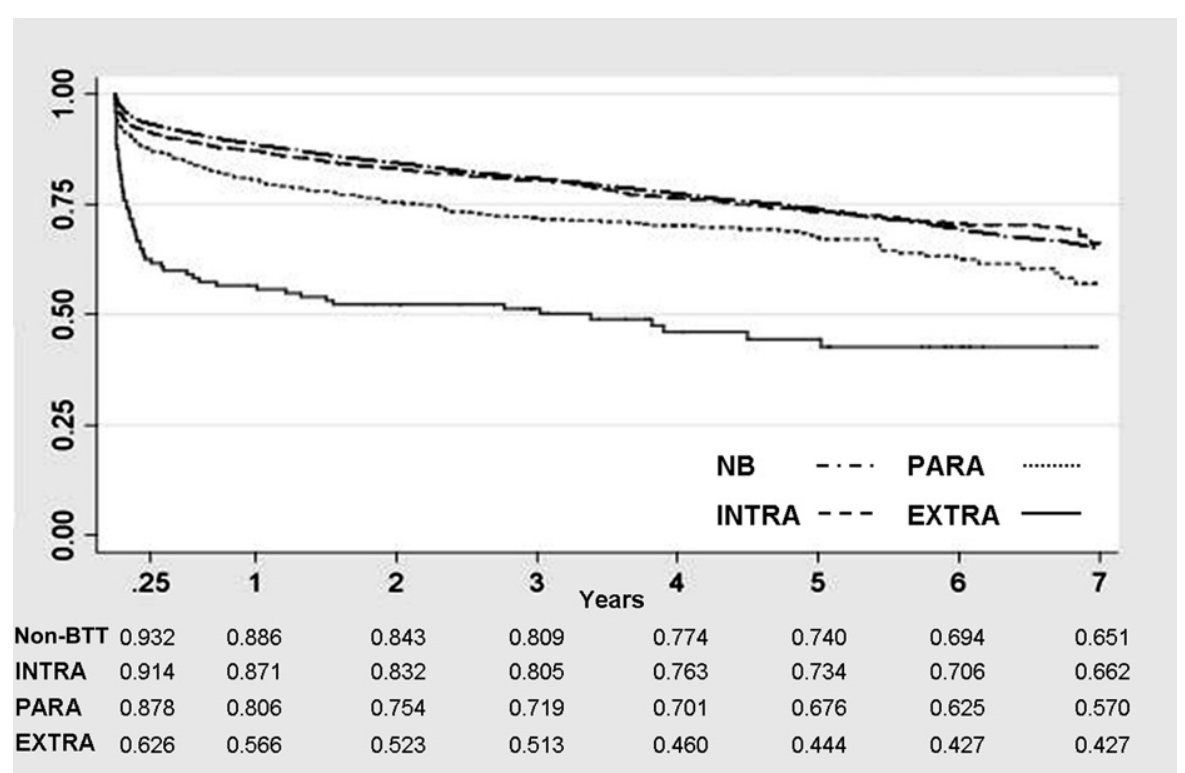

FIGURE 1. Kaplan-Meier unadjusted graft survival by group. Non-BTT, Nonbridge to transplant; INTRA, intracorporeal ventricular assist device; PARA, paracorporeal ventricular assist device; EXTRA, extracorporeal ventricular assist device.

$0.79,0.40-1.55, P=.488)$. However, risk-adjusted graft survival at more than 5 years was significantly better in the pulsatile group $(0.277,0.122-0.627, P=.002)$. The continuous-flow group lacked sufficient follow-up to calculate a hazard ratio beyond 5 years. In the pulsatile and continuous-flow groups, only infection was increased during the transplant hospitalization. There were no differences in the incidence rates of long-term complications in either pulsatile or continuous-flow groups when compared with the non-BTT group.

\section{DISCUSSION}

Findings here demonstrate that posttransplant survival among recipients bridged to transplantation with LVADs differs by device type. Among recipients bridged with extracorporeal devices (EXTRA group), survival was diminished in the short term $(<90$ days). However, survival in recipients bridged with either paracorporeal or intracorporeal implantable devices (PARA and INTRA groups) was not statistically diminished from that of nonbridged recipients (non-BTT group) at any posttransplant

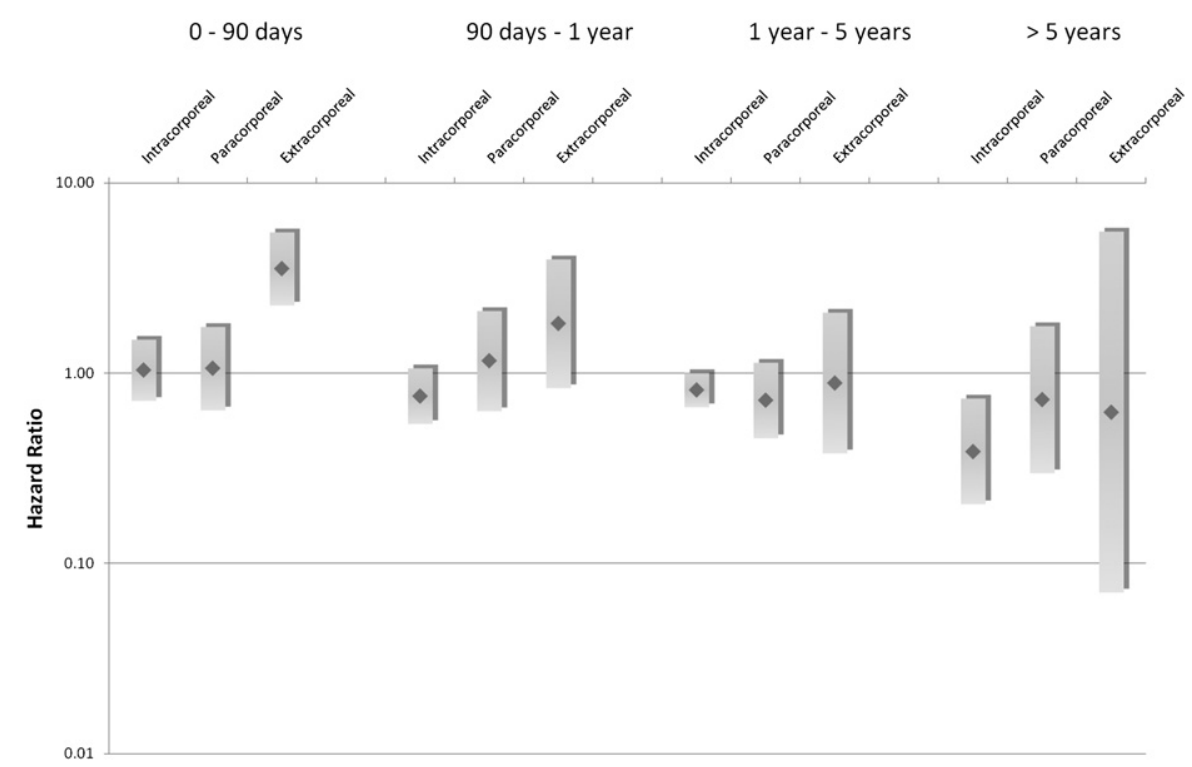

FIGURE 2. Hazard ratios and $95 \%$ confidence intervals for graft survival at follow-up intervals where compared with nonbridge. 


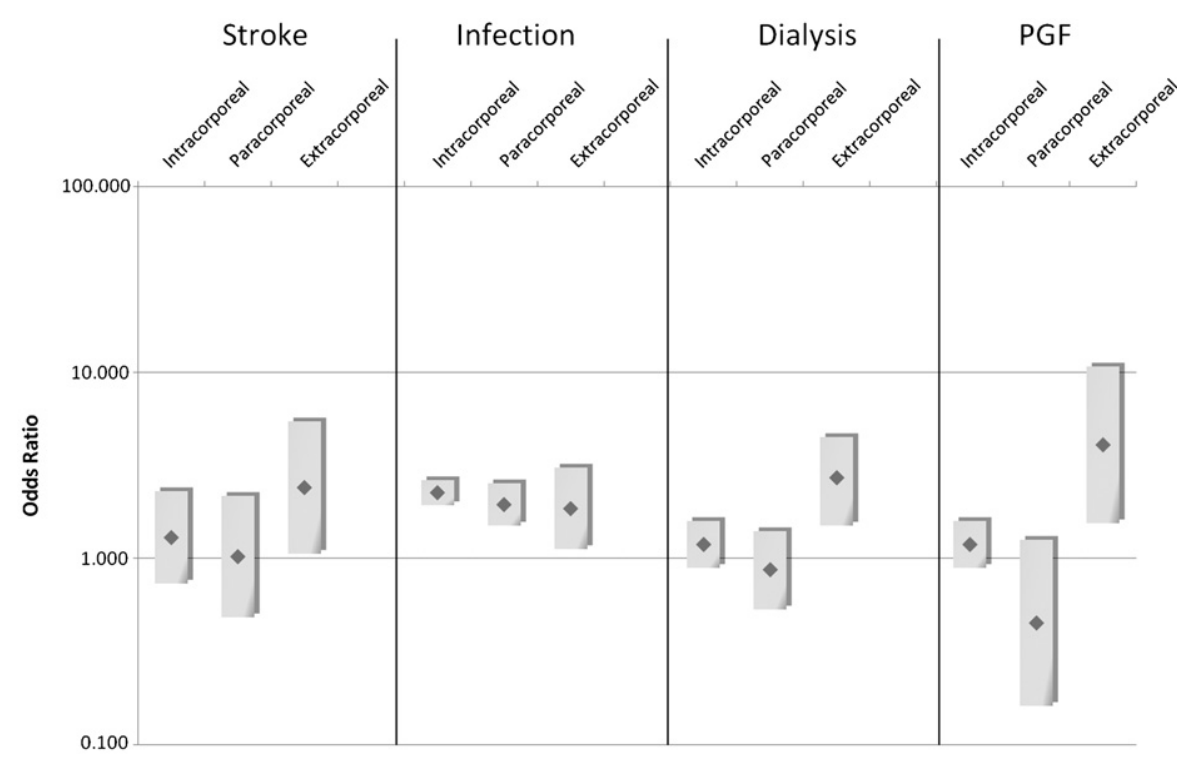

FIGURE 3. Odds ratios and $95 \%$ confidence intervals for in-hospital complications when compared with nonbridge. $P G F$, Primary graft failure at 30 days.

time interval $(<90$ days, 90 days -1 year, $1-5$ years). Furthermore, risk-adjusted survival at more than 5 years was found to be significantly better in the INTRA group than the non-BTT group.

\section{Survival}

In the EXTRA group, the diminished early survival is not surprising. Extracorporeal devices are more frequently used in acutely decompensated patients. Furthermore, these devices are limited to shorter durations of support; therefore, there is less opportunity to optimize candidates. As a result, a large percentage of recipients supported with extracorporeal devices remain critically ill at the time of transplantation. This is reflected by higher percentages of EXTRA recipients with status $1 \mathrm{~A}$ listing, requiring inotropic support, hospitalized in the intensive care unit, and intubated at the time of transplant. In addition, more than $10 \%$ of EXTRA recipients underwent a prior transplant within 90 days, compared with less than $1.0 \%$ in the other 3 groups. Given the retrospective nature of this study, a causal relationship between posttransplant survival and device type cannot be further delineated. The diminished posttransplant survival in the EXTRA group likely reflects, at least in part, differences in the recipients and not inherent differences in the devices. However, even if recipients with high-risk characteristics such as retransplant within 90 days and/or intubation at the time of transplantation were excluded from analysis, graft survival at more than 90 days in multivariate regression remained significantly worse among the EXTRA group.

INTRA and PARA groups achieved better posttransplant outcomes than EXTRA recipients, although, compared with the PARA group, both unadjusted and risk-adjusted survival was better in the INTRA group.
During this study period, there was a trend toward better risk-adjusted survival in the INTRA group than in the NB group at later time points (90 days -1 year and $1-5$ years). Interestingly, risk-adjusted survival at more than 5 years was significantly better in the INTRA group than the NB group. This is in contrast to the recent study ${ }^{6}$ of heart transplant recipients between 1995 and 2004, which noted a significant increase in late mortality among those bridged with intracorporeal devices. There is no clear explanation for better graft survival at more than 5 years among the INTRA group compared with the NB group found in this current study.

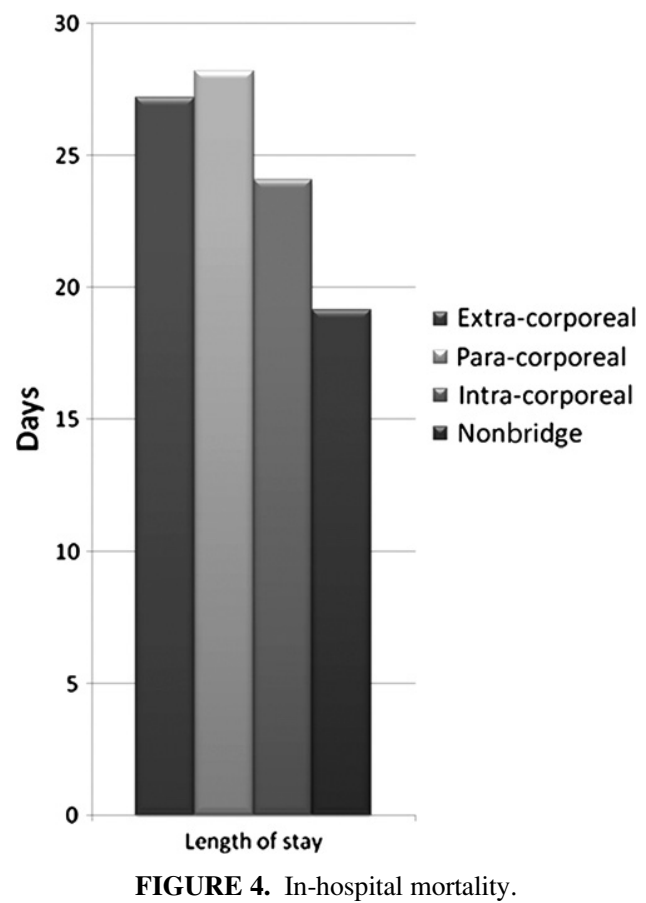




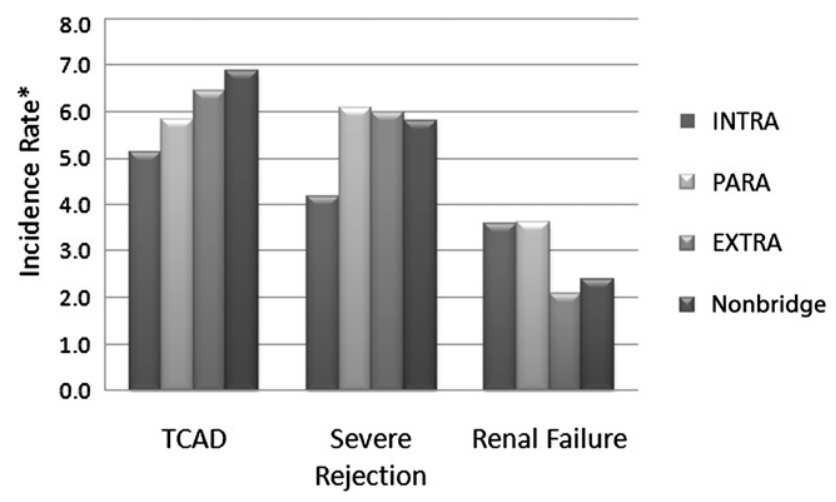

FIGURE 5. Long-term complications of transplantation by group. *Transplant coronary artery disease $(T C A D)$ and severe rejection were reported as incidence rates per 100 patient-years; renal failure was reported per $1000 \mathrm{pa}-$ tient-years. INTRA, Intracorporeal ventricular assist device; PARA, paracorporeal ventricular assist device; EXTRA, extracorporeal ventricular assist device.

However, in their analysis, Patlolla and associates ${ }^{6}$ found that, when compared with the reference group, the INTRA group had significantly better survival at 2 to 3 years and a trend toward better survival at 4 to 5 years. This finding may be related to the pretransplant characteristics in the INTRA group, including lower mean age, higher percentage of primary transplants, and lower percentage of congenital etiology.

The conflicting findings between this current study and the earlier study by Patlolla and associates ${ }^{6}$ regarding survival for more than 5 years may reflect the improvements in outcomes during the more recent study period that are associated with operator learning curves, volume-outcome effect, and/or technological advances in intracorporeal device therapy, including durability, greater ease of explant, and more favorable adverse event profiles. Alternatively, they may reflect the statistical limitations of analyzing this earlier time period (Appendix E2). Other possible explanations for the differing findings may result from differences in study design, including the primary end point, inclusion/exclusion criteria, and population of data fields. We chose to use graft survival as the primary end point. In our opinion, graft survival has a number of advantages over patient survival. As organs available for transplant remain critically scarce, further expanding the benefit of transplantation is predicated on improving the use of organs available for transplantation. Analysis focusing on graft survival rather than patient survival better addresses this important issue. Moreover, if recipients receive multiple transplants during the study period, survival obtained after retransplantation is double counted. That is, patient survival for recipients undergoing transplantation twice during the study period is the sum of survival as a result of the initial transplant plus the survival after the second transplant; patient survival after the second transplant will also be included in analysis as a second, dis- tinct observation, and thus be counted twice. Finally, using patient survival in regression analysis significantly confounds the model by allowing for a bailout strategy of retransplant and introduces greater confounding by leaving factors unaccounted for in the model, including the timing of the retransplant, recipient clinical status at the time of the repeat transplant, and characteristics of the donor involved in the retransplant. A second difference between this current study and the study by Patlolla and colleagues ${ }^{6}$ was that this current analysis included status 2 recipients and retransplanted recipients. However, each of these variables was accounted for in regression analysis; therefore, it is unlikely that this difference should influence the findings.

\section{Short- and Long-Term Morbidity}

The VAD groups generally experienced greater perioperative morbidity and longer lengths of stay. Not surprisingly, the incidence of infection during the transplant hospitalization was higher in all VAD groups. However, infection rates were not lower in the INTRA group; this may reflect longer duration of support. Furthermore, only the EXTRA group had increased risks of dialysis, stroke, and primary graft failure at 30 days compared with the non-BTT group. Finally, consistent with previous studies, ${ }^{11-13}$ the long-term complications of transplantation, including the incidence of chronic dialysis, transplant coronary artery disease, and severe rejection, did not differ across groups.

\section{Pulsatile Versus Continuous-Flow Devices}

Secondary analysis further stratified the INTRA group into 2 subgroups, pulsatile and continuous flow. When either of these groups was compared with the NB group, there was no statistical difference in graft survival, in-hospital morbidity, or long-term complications of transplantation except at more than 5 years, where graft survival, as in the INTRA group, was significantly better in recipients bridged with pulsatile devices.

\section{Implications}

First, although heart transplant recipients bridged to transplantation with VADs are typically considered to be at higher risk in the posttransplant period, findings from this analysis demonstrate that outcomes differ by device type. This may be due to differences in baseline characteristics and operative procedures. Recipients bridged with implantable devices still achieve the same unadjusted survival as nonbridged recipients. In contrast, candidates supported by extracorporeal devices remain at high risk in the early posttransplant period. However, the diminished posttransplant survival in the EXTRA group may, at least in part, reflect differences in the recipients and not inherent differences in the devices.

These findings presented here-in conjunction with a number of recent studies demonstrating that more than $80 \%$ of well-selected patients implanted with intracorporeal 
devices as a bridge to transplantation are successfully transplanted $^{14,15}$ — provide additional evidence that more aggressive use of implantable devices may benefit candidates whose condition is refractory to medical management. Because outcomes are best when implantable device support is implemented before patients acutely decompensate, ${ }^{14,15}$ these findings further suggest that more aggressive use of implantable support may benefit candidates who are likely to face long waiting times, such as candidates with higher body mass index or blood type $\mathrm{O}$. Conversely, this analysis found that during the study period recipients bridged with extracorporeal devices possessed high-risk characteristics and achieved inferior outcomes in the early posttransplant period. Therefore, candidates supported by an extracorporeal device may benefit from further optimization before transplantation, and extracorporeal devices may best be used as a bridge to an implantable device. However, given the retrospective nature of this study, additional studies examining outcomes among heart transplant candidates during both waiting and posttransplant periods are needed. Furthermore, an additional analysis should focus on assessing the survival of heart transplant candidates on the waiting list in the absence of mechanical support.

\section{Limitations}

Patient registries often suffer from data entry variability. However, fields contained within this database were generally well populated with a $95 \%$ to $99 \%$ data entry rate for the majority of variables. Although the UNOS reporting system provided variable definitions in data guidelines, definitions may still differ by center. Second, the limited time points for collection of data in the UNOS registry (at listing, at transplantation, and at follow-up) preclude the analysis of clinical status at the time of device implantation or over the course of mechanical support. As such, we could not analyze the length of time supported by a particular device, which might have been a particularly strong predictor of end-organ dysfunction and poor outcome. Nevertheless, future studies are needed to better elucidate the important and complex relationship between time on device support and posttransplant outcomes.

Device information for recipients was missing in a small number of cases and was ambiguous in others. Devices designated as only as "Abiomed" were classified as "Abiomed BVS5000," and devices designated as only as "Thoratec" were classified as "Thoratec PVAD." Regardless, this is unlikely to have a significant impact on the findings. During the study period, the experience with the Abiomed AB 5000 device was limited to approximately 25 patients, ${ }^{16}$ and posttransplant outcomes in recipients bridged with the Thoratec devices-PVAD, HMI, and HMII-did not differ significantly.

Although our regression model demonstrated moderate discrimination, significant variability remains unexplained. We speculate that some of the variability stems from functional status, health variables, and technical aspects of the procedure that were not captured by the UNOS data set. As a result, differences among the EXTRA, PARA, and INTRA groups may, at least in part, reflect differences in the recipients and not inherent differences related to the devices types.

\section{CONCLUSIONS}

Posttransplantation graft survival in recipients bridged to transplantation with LVADs differs by VAD type. During the study period, the use of implantable LVADs as bridges to transplantation, including both intracorporeal and paracorporeal devices, was not associated with diminished risk-adjusted posttransplant graft survival compared with nonbridged recipients. However, risk-adjusted posttransplant graft survival at less than 90 days was diminished in recipients bridged with extracorporeal devices.

These findings support the aggressive use of implantable devices in candidates who are refractory to medical management, especially those who are expected to encounter long waiting times. Conversely, outcomes in the EXTRA group suggest that the candidates supported by an extracorporeal device may need further optimization before transplantation; therefore, extracorporeal devices may best be used as a bridge to an implantable device. Nevertheless, given the retrospective nature of this study, additional studies examining outcomes among heart transplant candidates during both waiting and posttransplant periods are needed.

We thank UNOS for supplying this data and Katarina Anderson, $\mathrm{PhD}$, for her assistance with our analysis.

\section{References}

1. Frazier OH, Rose EA, Oz MC, Dembitsky W, McCarthy P, Radovancevic B, et al. for the HeartMate LVAS Investigators. Left ventricular assist system. Multicenter clinical evaluation of the HeartMate vented electric left ventricular assist system in patients awaiting heart transplantation. J Thorac Cardiovasc Surg. 2001;122: 1186-95.

2. Miller LW, Pagani FD, Russell SD, John R, Boyle AJ, Aaronson KD, et al. Use of a continuous-flow device in patients awaiting heart transplantation. HeartMate II Clinical Investigators. N Engl J Med. 2007;357:885-96.

3. UNOS STAR database.

4. Cleveland JC Jr, Grover FL, Fullerton DA, Campbell DN, Mitchell MB, Lindenfeld $\mathbf{J}$, et al. Left ventricular assist device as bridge to transplantation does not adversely affect one-year heart transplantation survival. J Thorac Cardiovasc Surg. 2008;136:774-7.

5. Taylor DO, Edwards LB, Aurora P, Christie JD, Dobbels F, Kirk R, et al. Registry of the International Society for Heart and Lung Transplantation: twenty-fifth official adult heart transplant report-2008. J Heart Lung Transplant. 2008;27:943-56.

6. Patlolla V, Patten RD, Denofrio D, Konstam MA, Krishnamani R. The effect of ventricular assist devices on post-transplant mortality: an analysis of the United Network for Organ Sharing thoracic registry. J Am Coll Cardiol. 2009;53:264-71.

7. Rose EA, Gelijns AC, Moskowitz AJ, Heitjan DF, Stevenson LW, Dembitsky W, et al. for the Randomized Evaluation of Mechanical Assistance for the Treatment of Congestive Heart Failure (REMATCH) Study Group. Long-term mechanical left ventricular assistance for end-stage heart failure. $N$ Engl J Med. 2001;345: 1435-43.

8. Dowling RD, Park SJ, Pagani FD, Tector AJ, Naka Y, Icenogle TB, et al. HeartMate VE LAS design enhancements and its impact on device reliability. Eur $J$ Cardiothorac Surg. 2004;25:958-63.

9. Miller LW, Nelson KE, Bostic RR, Tong K, Slaughter MS, Long JW. Hospital costs for left ventricular assist devices for destination therapy: lower costs for 
implantation in the post-REMATCH era. $J$ Heart Lung Transplant. 2006;25: 778-84.

10. John R, Kamdar F, Liao K, Colvin-Adams M, Boyle A, Joyce L. Improved survival and decreasing incidence of adverse events with the HeartMate II left ventricular assist device as bridge-to-transplant therapy. Ann Thorac Surg. 2008;86:1227-34.

11. Radovancevic B, Golino A, Vrtovec B, Thomas CD, Radovancevic R, Odegaard P, et al. Is bridging to transplantation with a left ventricular assist device a risk factor for transplant coronary artery disease? J Heart Lung Transplant. 2005;24:703-7.

12. Gonzalez-Stawinski GV, Cook DJ, Chang AS, Atik F, Navia JL, Banbury M, et al. Early and midterm risk of coronary allograft vasculopathy in patients bridged to orthotopic heart transplantation with ventricular assist devices. Transplantation. 2005;79:1175-9.

13. Kirsch L, Timmermans T, Van Caenegem O, Gurne O, Noirhomme P, Jacquet LM, et al. Allosensitization in bridge to transplant Novacor left ventricular assist device patients: analysis of long-term outcomes with regard to acute rejection and chronic allograft vasculopathy. Eur J Cardiothorac Surg. 2008;34:268-74.

14. Russo MJ, Chen JM, Argenziano M, Gelijns AC, Moskowitz AJ, Ascheim DC, et al. Preoperative screening scale predicts successful bridge to transplantation in chronic congestive heart failure patients. Proceedings of the Society of Thoracic Surgeons Annual Meeting; 2007; San Diego.

15. Boyle A, Ascheim DD, Russo MJ, Kormos R, John R, Naka Y, et al. LVAD Implantation in Less Acutely Ill Heart Failure Patients: Do Current Data Justify the Strategy? Proceedings of the 2008 European Society of Cardiology Heart Failure Congress; 2008; Milan, Italy.

16. Dowling RD, Gray LA Jr, Etoch SW, Laks H, Marelli D, Samuels L, et al. Initial experience with the AbioCor implantable replacement heart system. I Thorac Cardiovasc Surg. 2004;127:131-41. 
APPENDIX E1. Multivariate Cox proportional hazards regression analysis

\begin{tabular}{|c|c|c|c|c|}
\hline \multirow{2}{*}{$\begin{array}{c}\text { VAD type } \\
\text { by posttransplant } \\
\text { interval } \\
\end{array}$} & \multirow[b]{2}{*}{ Hazard ratio } & \multicolumn{3}{|c|}{$95 \%$ Confidence interval } \\
\hline & & $\begin{array}{l}95 \% \\
\text { CI LL }\end{array}$ & $\begin{array}{l}95 \% \\
\text { CI UL }\end{array}$ & $P$ value \\
\hline \multicolumn{5}{|l|}{ 0-90 days } \\
\hline Intracorporeal & 1.040 & 0.715 & 1.505 & .834 \\
\hline Paracorporeal & 1.064 & 0.642 & 1.764 & .809 \\
\hline Extracorporeal & 3.540 & 2.275 & 5.507 & $<.001$ \\
\hline \multicolumn{5}{|l|}{90 days-1 year } \\
\hline Intracorporeal & 0.760 & 0.541 & 1.069 & .115 \\
\hline Paracorporeal & 1.164 & 0.636 & 2.131 & .621 \\
\hline Extracorporeal & 1.826 & 0.834 & 3.997 & .132 \\
\hline \multicolumn{5}{|l|}{$1-5$ years } \\
\hline Intracorporeal & 0.818 & 0.665 & 1.007 & .058 \\
\hline Paracorporeal & 0.723 & 0.457 & 1.145 & .166 \\
\hline Extracorporeal & 0.890 & 0.381 & 2.081 & .788 \\
\hline \multicolumn{5}{|l|}{$>5$ years } \\
\hline Intracorporeal & 0.389 & 0.205 & 0.738 & .004 \\
\hline Paracorporeal & 0.728 & 0.298 & 1.780 & .487 \\
\hline Extracorporeal & 0.625 & 0.070 & 5.558 & .674 \\
\hline \multicolumn{5}{|l|}{ Other variables } \\
\hline Etiology: congenital & 1.592 & 1.259 & 2.012 & $<.001$ \\
\hline Recipient GFR & 0.988 & 0.985 & 0.991 & $<.001$ \\
\hline Recipient total bilirubin & 1.039 & 1.027 & 1.051 & $<.001$ \\
\hline Etiology: amyloid & 2.615 & 1.541 & 4.437 & $<.001$ \\
\hline Donor age & 1.010 & 1.006 & 1.013 & $<.001$ \\
\hline Hep C (+) donor & 2.286 & 1.532 & 3.410 & $<.001$ \\
\hline Recipient GFR $\times$ time $(y)$ & 0.865 & 0.798 & 0.939 & $<.001$ \\
\hline OHT center volume & 0.996 & 0.994 & 0.999 & .001 \\
\hline Ischemic time $\times$ time $(y)$ & 0.958 & 0.935 & 0.982 & .001 \\
\hline $\begin{array}{l}\text { Intubated at transplant } \times \\
\text { time (y) }\end{array}$ & 0.753 & 0.630 & 0.900 & .002 \\
\hline $\begin{array}{l}\text { Etiology: congenital } \times \\
\text { time }(y)\end{array}$ & 0.787 & 0.672 & 0.921 & .003 \\
\hline $\begin{array}{l}\text { Donor/recipient weight } \\
\text { ratio }<0.7\end{array}$ & 1.346 & 1.092 & 1.660 & .005 \\
\hline Intubated at transplant & 1.452 & 1.119 & 1.885 & .005 \\
\hline $\begin{array}{l}\text { Recipient diabetes } \\
\text { mellitus }\end{array}$ & 1.164 & 1.044 & 1.298 & .006 \\
\hline Ischemic time & 1.065 & 1.018 & 1.113 & .006 \\
\hline CMV $(+)$ recipient & 1.211 & 1.052 & 1.394 & .008 \\
\hline Recipient age $\times$ time $(\mathrm{y})$ & 0.997 & 0.995 & 0.999 & .009 \\
\hline Recipient CVA $\times$ time $(y)$ & 0.871 & 0.781 & 0.970 & .012 \\
\hline $\begin{array}{l}\text { Female donor/female } \\
\text { recipient }\end{array}$ & 1.143 & 1.022 & 1.278 & .019 \\
\hline Etiology: $\mathrm{HCM} \times$ time $(\mathrm{y})$ & 0.729 & 0.557 & 0.953 & .021 \\
\hline $\begin{array}{l}\text { Donor DM }>6 \text { years } \times \\
\text { time }(y)\end{array}$ & 0.612 & 0.389 & 0.963 & .034 \\
\hline Hospitalized at transplant & 1.127 & 1.005 & 1.263 & .041 \\
\hline Reoperation & 1.107 & 0.992 & 1.234 & .069 \\
\hline $\begin{array}{l}\text { Male donor/female } \\
\text { recipient }\end{array}$ & 1.106 & 0.972 & 1.259 & .127 \\
\hline $\begin{array}{l}\mathrm{CMV}(-) \text { recipient/(+) } \\
\quad \text { donor }\end{array}$ & 1.134 & 0.965 & 1.334 & .128 \\
\hline Status 1A & 1.097 & 0.969 & 1.242 & .145 \\
\hline
\end{tabular}

APPENDIX E1. Continued

\begin{tabular}{|c|c|c|c|c|}
\hline \multirow{2}{*}{$\begin{array}{c}\text { VAD type } \\
\text { by posttransplant } \\
\text { interval }\end{array}$} & \multirow[b]{2}{*}{ Hazard ratio } & \multicolumn{3}{|c|}{$\mathbf{9 5} \%$ Confidence interval } \\
\hline & & $\begin{array}{l}95 \% \\
\text { CI LL }\end{array}$ & $\begin{array}{l}95 \% \\
\text { CI UL }\end{array}$ & $P$ value \\
\hline $\begin{array}{l}\text { DM complicated by PVD } \\
\text { or CKD }\end{array}$ & 1.192 & 0.937 & 1.516 & .153 \\
\hline ICU at transplant & 0.902 & 0.780 & 1.042 & .161 \\
\hline Recipient age & 0.997 & 0.992 & 1.002 & .190 \\
\hline Recipient underweight & 1.173 & 0.922 & 1.494 & .195 \\
\hline Donor history of cancer & 0.801 & 0.540 & 1.186 & .268 \\
\hline Etiology: valvular & 0.854 & 0.640 & 1.139 & .282 \\
\hline Transplant year & 1.017 & 0.986 & 1.050 & .285 \\
\hline $\begin{array}{l}\text { BMI obesity } \\
\text { class II/III }\end{array}$ & 1.110 & 0.890 & 1.385 & .354 \\
\hline Etiology: ischemic & 1.051 & 0.938 & 1.176 & .391 \\
\hline Etiology: HCM & 0.849 & 0.580 & 1.242 & .399 \\
\hline Status 1B & 1.080 & 0.903 & 1.292 & .400 \\
\hline BiVAD at transplant & 1.172 & 0.805 & 1.705 & .407 \\
\hline $\begin{array}{l}\text { Female donor/male } \\
\text { recipient }\end{array}$ & 1.082 & 0.898 & 1.304 & .409 \\
\hline Hep C $(+)$ recipient & 1.120 & 0.840 & 1.493 & .440 \\
\hline Recipient CVA & 1.076 & 0.893 & 1.295 & .442 \\
\hline $\begin{array}{l}\text { Donor cause } \\
\text { of death: cancer }\end{array}$ & 1.221 & 0.726 & 2.054 & .452 \\
\hline Etiology: other & 0.901 & 0.683 & 1.189 & .462 \\
\hline $\begin{array}{l}\text { Corticosteroids at } \\
\text { transplant }\end{array}$ & 1.061 & 0.903 & 1.246 & .471 \\
\hline $\begin{array}{l}\text { Donor cause } \\
\text { of death: hypertension }\end{array}$ & 1.059 & 0.899 & 1.247 & .494 \\
\hline Insulin-dependent donor & 1.182 & 0.625 & 2.236 & .607 \\
\hline Recipient COPD & 1.057 & 0.826 & 1.352 & .660 \\
\hline Etiology: sarcoid & 0.819 & 0.305 & 2.196 & .691 \\
\hline $\begin{array}{l}\text { No. of previous } \\
\text { heart transplants }\end{array}$ & 1.073 & 0.730 & 1.577 & .721 \\
\hline Donor DM $>6$ years & 1.118 & 0.568 & 2.201 & .746 \\
\hline $\begin{array}{l}\text { Donor cause } \\
\text { of death: CVA }\end{array}$ & 1.029 & 0.859 & 1.233 & .754 \\
\hline $\begin{array}{l}\text { Corticosteroids at } \\
\quad \text { transplant } \times \text { time }(y)\end{array}$ & 1.008 & 0.932 & 1.090 & .837 \\
\hline $\begin{array}{l}\text { Corticosteroids at } \\
\quad \text { transplant } \times \text { time }(\mathrm{y})\end{array}$ & 1.019 & 0.609 & 1.706 & .943 \\
\hline $\begin{array}{l}\text { Previous OHT within } 90 \\
\text { days }\end{array}$ & 1.003 & 0.436 & 2.309 & .994 \\
\hline
\end{tabular}

$V A D$, Ventricular assist device; $C I$, confidence interval; $L L$, lower limit; $U L$, upper limit; GFR, glomerular filtration rate; $H e p C$, hepatitis $\mathrm{C}$; $O H T$, orthotopic heart transplant; $C M V$, cytomegalovirus; $C V A$, cerebrovascular accident; $H C M$, hypertrophic cardiomyopathy; $D M$, diabetes mellitus; $P V D$, peripheral vascular disease; $C K D$, chronic kidney disease; $I C U$, intensive care unit; $B i V A D$, biventricular assist device; $C O P D$, chronic obstructive pulmonary disease. 


\section{APPENDIX E2}

On the basis of our analysis of the UNOS database, it appears that the study reported by Patlolla and associates ${ }^{6}$ is plagued by missing data. During the 1995 to 2004 time period, UNOS reported that 13,891 status $1 / 1 \mathrm{~A} / 1 \mathrm{~B}$ recipients underwent transplantation. On the basis of the study's exclusion criteria-retransplantation $(\mathrm{n}=233)$, VAD and intraaortic balloon pump concurrently $(\mathrm{n}=185)$, multiorgan transplant $(\mathrm{n}=238), 13,258$ met inclusion criteria. However, Patlolla and associates ${ }^{6}$ included only 11,336 status 1 recipients in their analysis. Furthermore, we identified 2788 status 1 BTT recipients who met inclusion criteria; however the study in the Journal of the American College of Cardiology included only 1881 BTT recipients in the analysis.

Determining VAD type in the UNOS registry is complicated. VAD type is not coded by a single field. Rather, it may be indicated in as many as 8 separate fields: vad_brand1_trr, vad_brand2_trr, vad_tah_trr, vad_device_ty_trr, vad_brand1_ostxt_trr, vad_brand2_ostxt_trr, vad_tah_ostxt_trr, and oth_life_sup_ostxt_trr. The last 4 fields are free text and require that analysts search observations by hand to ensure accurate categorization. Furthermore, in 1999, UNOS expanded the data entry options, thus improving the ability of centers to more clearly specify VAD type. Before this, a significant portion of bridged recipients were merely coded as "LVAD," "VAD," or "VAD/unspecified." Therefore, VAD type (intracorporeal vs extracorporeal) cannot be determined. As summarized below "VAD/unspecified" described more than $70 \%$ of the recipients bridged to transplant before 1999 (Appendix E2 Table).

On the basis of the Methods section contained in the article, it was difficult to understand how the authors dealt with recipients with missing data. In addition, it is unclear from the manuscript how they accounted for the DeBakey, Jarvik, HeartMate 2, Thoratec and IVAD devices, as well as total artificial hearts and extracorporeal membrane oxygenation-all of which were used to successfully bridge recipients to transplantation during their study period. Moreover, we disagree with the classification of VAD type in the study by Patlolla and associates. ${ }^{6}$ In their analysis, the intracorporeal VAD group included patients on a HeartMate (Thoratec Corporation, Pleasanton, Calif) or Novacor (World Heart Inc, Oakland, Calif) intracorporeal VAD. The extracorporeal
VAD group included patients with a Thoratec (Thoractec Corporation) or Abiomed (Abiomed Inc, Danvers, Mass) extracorporeal VAD. However, we consider the Thoratec device to be a paracorporeal, not extracorporeal device.

Based on of communication with the Journal of the American College of Cardiology authors, they included only specified VAD types-HeartMate and Novacor in the intracorporeal group and Thoratec and Abiomed devices in the extracorporeal group. If the type was another device type or "unspecified," they assumed that the device was not one of these devices, and they excluded the recipient from analysis. This strategy has significant limitations, unless it is assumed that the missing data were random. However, given the high proportion of missing data, this is a poor assumption.

The Journal of the American College of Cardiology article's most significant finding was that late ( $>5$ years), but not early, survival differed in the implantable device group compared with the non-BTT group. This finding is significant because previous studies comparing posttransplant outcomes in BTT and non-BTT recipients, like most studies comparing "high-risk" surgical populations and standard populations, generally found that the BTT population falls into 1 of 3 categories: (1) no survival difference, (2) early (first 90 days to 1 year) survival difference with this difference persisting over the long term, and (3) early survival difference with no difference over the long term. To have a difference in late but not early survival is inconsistent with previously published studies of this population. Furthermore, with previous studies concluding that the longterm complications of transplantation, including rejection, infection, and transplant coronary artery disease, do not differ in these groups, there is no obvious clinical explanation for this finding.

Any analysis of the time period including 1995 through 1999 is significantly confounded by missing data. For the Journal of the American College of Cardiology article, this issue of confounding is most relevant in this later follow-up period. In this study, follow-up data were available only through 2006; therefore, recipients with greater than 5 years of follow-up underwent transplantation in the period of 1995 to 2000. During this era, by our analysis, significantly more than $50 \%$ of the study group was dropped from analysis. Therefore, it is difficult to draw any conclusions regarding this time period. 
APPENDIX E2 TABLE.

\begin{tabular}{|c|c|c|c|c|c|}
\hline Year & EXTRA & INTRA & PARA & $\begin{array}{c}\mathrm{VAD} / \\
\text { unspecified }\end{array}$ & Total \\
\hline \multirow[t]{2}{*}{1995} & 2 & 24 & 0 & 132 & 158 \\
\hline & 1.27 & 15.2 & 0 & 83.5 & \\
\hline \multirow[t]{2}{*}{1996} & 1 & 29 & 3 & 173 & 206 \\
\hline & 0.49 & 14.1 & 1.46 & 84.0 & \\
\hline \multirow[t]{2}{*}{1997} & 0 & 53 & 1 & 188 & 242 \\
\hline & 0 & 21.9 & 0.41 & 77.7 & \\
\hline \multirow[t]{2}{*}{1998} & 7 & 63 & 1 & 166 & 237 \\
\hline & 2.95 & 26.6 & 0.42 & 70.0 & \\
\hline \multirow[t]{2}{*}{1999} & 8 & 123 & 7 & 122 & 260 \\
\hline & 3.08 & 47.3 & 2.7 & 46.9 & \\
\hline \multirow[t]{2}{*}{2000} & 23 & 256 & 20 & 3 & 302 \\
\hline & 7.62 & 84.7 & 6.6 & 0.99 & \\
\hline \multirow[t]{2}{*}{2001} & 29 & 288 & 86 & 0 & 403 \\
\hline & 7.2 & 71.5 & 21.3 & 0 & \\
\hline \multirow[t]{2}{*}{2002} & 14 & 262 & 64 & 3 & 343 \\
\hline & 4.08 & 76.4 & 18.7 & 0.87 & \\
\hline \multirow[t]{2}{*}{2003} & 10 & 239 & 89 & 4 & 342 \\
\hline & 2.92 & 69.9 & 26.0 & 1.17 & \\
\hline \multirow[t]{2}{*}{2004} & 6 & 247 & 37 & 5 & 295 \\
\hline & 2.03 & 83.7 & 12.5 & 1.69 & \\
\hline \multirow[t]{2}{*}{ Total } & 100 & 1584 & 308 & 796 & 2788 \\
\hline & 3.59 & 56.8 & 11.1 & 28.6 & \\
\hline
\end{tabular}

$\overline{\text { EXTRA, Extracorporeal ventricular assist device. INTRA, intracorporeal ventricular }}$ assist device; $P A R A$, paracorporeal ventricular assist device; $V A D$, ventricular assist device.

EXTRA devices included Abiomed BVS5000, Tandem, Bio-Medicus, and Levitronix/Centrimag. PARA devices included Abiomed AB5000, Thoratec PVAD, and Toyobo. INTRA devices included pulsatile devices (Novacor, HeartMate I, Thoratec IVAD, and LionHeart) and continuous-flow devices (HeartMate II, MicroMed/De Bakey, Jarvik, and Ventracor/VentrAssist). Patients who had previously undergone transplantation or were also on an intra-aortic balloon pump were excluded. 